\title{
Mycophenolate for the treatment of primary Sjögren's syndrome
}

\author{
Weiqian Chen, Jin Lin
}

Division of Rheumatology, The First Affiliated Hospital, College of Medicine, Zhejiang University, Hangzhou, Zhejiang Province, China

\section{ABSTRACT}

Primary Sjögren's syndrome (pSS) is a systemic autoimmune disease with exocrine gland dysfunction and multi-organ involvement. Currently, there is an increasing trend toward non-steroid therapy for the treatment of autoimmune diseases. Some biological agents or immunosuppressive drugs may be the ideal choices. In real-world practice, as patients have severe systemic complications or organ damage, they will have a bad prognosis even if they are treated with high-dose steroids and strong immunosuppressive drugs. However, if we can start early intervention and prevent progressive development in advance, the patient may have a good prognosis. Mycophenolate is an immunosuppressive drug with minor side effects. Here, we conduct a systemic review and find supporting evidence that patients with pSS benefit from early mycophenolate therapy. Mycophenolate may be the first-line treatment for pSS patients in the future.

Key words: mycophenolate, Sjögren's syndrome

\section{INTRODUCTION}

Primary Sjögren's syndrome (pSS) is a chronic inflammatory autoimmune disease, which is most common in middle or elderly women. pSS is characterized by keratoconjunctivitis sicca and xerostomia due to focal lymphocytic infiltration to exocrine glands. The disease was originally considered benign at a stable phase. Now pSS is more thought of as a systemic disorder with the development of autoimmune cytopenia, synovitis, interstitial lung disease, neuropathy, renal disease, and vasculitis. ${ }^{[1]}$ Activated B lymphocytes are a hallmark of the disease, which is characterized by the presence of rheumatoid factor, hypergammaglobulinemia, anti$\mathrm{SSA} / \mathrm{Ro}$, and anti-SSB/La antibodies. ${ }^{[2]}$ Additionally, this disease has a higher risk of transformation to non-Hodgkin's lymphoma, which is much higher than other autoimmune diseases. ${ }^{[3]}$

The treatment of pSS largely depends on the alleviation of oral and ocular dryness.
Nevertheless, systemic treatment is more important in some patients with organ involvement. Hydroxychloroquine is the most well-studied medication in Sjogren's syndrome. However, recent clinical trials have shown disappointing effects of hydroxychloroquine in Sjogren's syndrome..$^{[4]}$ Moreover, biologics targeting mediators of autoimmune response are currently being explored in the treatment of pSS. Small trials using rituximab revealed an improvement in oral and ocular dryness, ${ }^{[5]}$ but this was not replicated in the large randomized controlled trials (RCTs). ${ }^{[6]}$ The patients who received rituximab were at a much higher cost when compared to placebo. ${ }^{[6]}$ Belimumab, which acts against B-cell activating factor (BAFF) systems, ameliorated the symptoms and decreased the overall disease activity in phase II study. ${ }^{[7]}$ Abatacept was well tolerated in patients with pSS. The disease activity index, rheumatoid factor, and $\operatorname{IgG}$ levels were all decreased, while fatigue and healthrelated quality of life improved over a $24-$ week period. ${ }^{[8]}$ Although the above drugs 
demonstrated efficiency, larger RCTs are still needed to confirm the results. In addition, the cost-effectiveness and convenience of medicine administration are important factors for the clinical application of biologics. Other biologics such as anti-IL1 (Anakinra) and anti-TNF- $\alpha$ agents were not proven to have efficacy in improving the symptoms of pSS..$^{[9,10]}$ Thus, there is an unmet need to find an effective and convenient treatment for pSS.

\section{MECHANISM OF MYCOPHENOLATE}

Mycophenolate mofetil (MMF) is a pro-drug of the active immunosuppressant mycophenolic acid (MPA). Mycophenolate sodium (MPS) is another MPA-containing compound similar to MMF. Mycophenolic acid can inhibit inosine monophosphate dehydrogenase, which leads to inhibition of the de novo pathway of nucleotide synthesis. The antiproliferative effect of MMF mainly affects activated $\mathrm{T}$ and $\mathrm{B}$ lymphocytes because the proliferation of these cells is critically dependent on the de novo purine synthesis compared with other eukaryotic cells. Mycophenolic acid results in decreased guanine synthesis and decreased DNA synthesis, decreased lymphocyte proliferation, and decreased antibody production without myelotoxicity.

Initially used to prevent rejection in solid-organ transplantation, ${ }^{[11]}$ MMF has been utilized as a steroidsparing agent in the treatment of autoimmune diseases including lupus nephritis and vasculitis. ${ }^{[12,13]}$ Walsh M considered MMF as first-line induction therapy for the treatment of lupus nephritis in patients without severe renal dysfunction. ${ }^{[14]}$ The guideline recommended MMF as a maintenance drug of lupus nephritis superior to azathioprine in terms of response and side effects. ${ }^{[15,16]}$ Since $\mathrm{T}$ and $\mathrm{B}$ lymphocytes have been suggested to play a pivotal role in the inflammation and immunopathogenesis of Sjogren's syndrome ${ }^{[17]} \mathrm{MMF}$ might be a promising agent in the treatment of Sjogren's syndrome.

\section{CURRENT EVIDENCE OF MYCOPHENOLATE IN THE TREATMENT OF PSS}

The past literature showed encouraging effects of mycophenolate on dryness symptoms and quality of life in patients with Sjogren's syndrome. ${ }^{[18-25]}$ Mycophenolate also has excellent immunomodulation effects on lupus nephritis. Currently, mycophenolate is widely used in lupus nephritis and organ transplant. For example, mycophenolate is well tolerated in transplant recipients and patients with lupus nephritis. In fact, mycophenolate has been commonly used for the treatment of pSS during clinical practice although there were not too many clinical trials. Here, we conduct a comprehensive review of the clinical application of mycophenolate in pSS.

Mycophenolate mofetil has been used as a maintaining drug after treatment with rituximab in patients with pSS. ${ }^{[18]}$ Combination therapy with intravenous immunoglobulin and MMF can successfully ameliorate the long-standing sensory neuronopathy in Sjögren's syndrome refractory to glucocorticoids and azathioprine. ${ }^{[19]}$ Others reported that MMF was revealed as an effective alternative to corticosteroids for the treatment of lymphocytic hypophysitis associated with pSS. ${ }^{[20]}$ Mycophenolate mofetil can also treat pSS with agranulocytosis refractory to high-dose prednisone, granulocyte-macrophage colony-stimulating factor, and cyclosporine. ${ }^{[21]}$ Neutrophil recovered to a normal level after 2 months. No neutropenia episodes occurred after 1 -year follow-up. Tubulointerstitial nephritis is usually caused by epithelial inflammation by pSS. It was reported that treatment with MMF can improve renal function. ${ }^{[22,23]}$ Furthermore, a single treatment with MMF or a combination of MMF and corticosteroids can ameliorate or maintain the stability of Sjögren sensory neuronopathy. ${ }^{[2]}$

Mycophenolate sodium is another MPA-containing compound similar to MMF. The efficacy and safety of MPS were first reported in 11 patients with pSS refractory to other immunosuppressive agents for 6 months. Mycophenolate was well tolerated in 8 of 11 patients. ${ }^{[25]}$ There was an improvement in ocular dryness on a visual analog scale and a reduced demand for artificial tear supplementations. However, no significant improvement in objective parameters for dryness of eyes and mouth was observed although a substantial improvement in glandular functions occurred in two patients with a short disease duration. Besides, treatment with MPS resulted in a significant reduction of hypergammaglobulinemia and IgM-rheumatoid factors as well as an increase in complement levels and white blood cells. However, the level of erythrocyte sedimentation rate (ESR) and anti-SSA/anti-SSB antibody titers did not change. Two patients did not complete the study due to vertigo or gastrointestinal side effect. One patient had pneumonia 2 weeks after treatment and was withdrawn. ${ }^{[25]}$

Another immunosuppressive drug such as azathioprine has been only reported as helpful in cases of systemic complications such as lung disease ${ }^{[26]}$ and myelopathy ${ }^{[27]}$ but not in a double-blind placebo controlled trial. ${ }^{[28]}$ Moreover, it was not recommended for the treatment of pSS without systemic complications. There is a high frequency of side effects after the use of azathioprine. Similarly, pSS patients with systemic complications such as pneumonitis may benefit little from ciclosporin A or 
cyclophosphamide therapy with some side effects. ${ }^{[29,30]}$ However, ciclosporin A is not routinely recommended for the management of uncomplicated Sjögren's syndrome although it may be helpful in patients with significant joint involvement. ${ }^{[31]}$

When compared to other immunosuppressants such as methotrexate, leflunomide, and azathioprine are there any advantages of MMF? Methotrexate is a disease-modifying anti-rheumatic drug (DMARD), which is preferred to be used in patients with arthritis diseases such as rheumatoid arthritis (RA), juvenile idiopathic arthritis (JIA), and psoriatic arthritis (PsA). Leflunomide is another DMARD for the treatment of arthritis diseases, for example, RA and a few diffuse connective tissue diseases such as systemic lupus erythematosus (SLE). Although it was reported in patients with pSS, the efficacy of leflunomide was not good enough in phase II pilot study. ${ }^{[32]}$ Azathioprine and mycophenolate were two immunosuppressants used for many diffuse connective tissue diseases such as SLE, lupus nephritis (LN), and myositis. The fateful agranulocytosis is the severe hematological side effect of azathioprine. However, the safety profile seems fairly acceptable in the treatment using mycophenolate.

\section{MYCOPHENOLATE MAY BE THE FIRST-LINE TREATMENT FOR PSS}

Currently, there is an increasing trend toward non-steroid therapy for the treatment of autoimmune diseases. Some biological agents or immunosuppressive drugs may be the ideal choices. In real-world practice, as the patients have severe systemic complications or organ damage, they will have a bad prognosis even after treatment with high-dose steroids and strong immunosuppressive drugs (such as cyclophosphamide). However, if we can start early intervention and prevent progressive development in advance, patients may have a good prognosis. Mycophenolate mofetil is an immunosuppressive drug with minor side effects and is available in China. Mycophenolate mofetil usually was considered as secondline treatment in pSS patients who were refractory to steroid or cyclophosphamide. At our medical center, 60 new-onset pSS patients with high IgG and ESR but without systemic involvement received MMF at an early stage. They showed good response to this drug with the alleviation of oral and ocular dryness without severe side effects. Furthermore, there was also a significant reduction in ESR and IgG levels (unpublished data). We think many patients with pSS will benefit from this therapy. The recent European League Against Rheumatism (EULAR) recommendations do not support the choice of one immunosuppressive agent over another. We think the main reason is lack of high-quality studies in this area. ${ }^{[33]}$ In the future, large double-blind RCTs will find the affirmative effect of MMF in new-onset pSS patients.

\section{Competing interests}

The authors declare no competing interests.

\section{Source of Funding}

This study was supported by National Natural Science Foundation of China (81701600), Zhejiang Provincial Natural Science Foundation of China (LQ17H100001, LGF18H100001), and the Research Medical and Health Program of Zhejiang Province (2019RC032).

\section{REFERENCES}

1. Fox PC. Autoimmune diseases and sjogren's syndrome: An autoimmune exocrinopathy. Ann N Y Acad Sci 2007; 1098: 15-21.

2. Mackay F, Groom JR, Tangye SG. An important role for b-cell activation factor and $b$ cells in the pathogenesis of sjogren's syndrome. Curr Opin Rheumatol 2007; 19: 406-13.

3. Ekstrom Smedby K, Vajdic CM, Falster M, Engels EA, Martinez-Maza $\mathrm{O}$, Turner J, et al. Autoimmune disorders and risk of non-hodgkin lymphoma subtypes: A pooled analysis within the interlymph consortium. Blood 2008; 111: 4029-38.

4. Gottenberg JE, Ravaud P, Puechal X, Le Guern V, Sibilia J, Goeb V, et al. Effects of hydroxychloroquine on symptomatic improvement in primary sjogren syndrome: The joquer randomized clinical trial. JAMA 2014; 312: 249-58.

5. Devauchelle-Pensec V, Mariette X, Jousse-Joulin S, Berthelot JM, Perdriger A, Puechal X, et al. Treatment of primary sjogren syndrome with rituximab: A randomized trial. Ann Intern Med 2014; 160: 233-42.

6. Bowman SJ, Everett CC, O’Dwyer JL, Emery P, Pitzalis C, Ng WF, et al. Randomized controlled trial of rituximab and cost-effectiveness analysis in treating fatigue and oral dryness in primary sjogren's syndrome. Arthr Rheumatol (Hoboken, N.J.) 2017; 69: 1440-50.

7. Mariette X, Seror R, Quartuccio L, Baron G, Salvin S, Fabris M, et al. Efficacy and safety of belimumab in primary sjogren's syndrome: Results of the beliss open-label phase ii study. Ann Rheum Dis 2015; 74: 526-31.

8. Meiners PM, Vissink A, Kroese FG, Spijkervet FK, Smitt-Kamminga NS, Abdulahad WH, et al. Abatacept treatment reduces disease activity in early primary sjogren's syndrome (open-label proof of concept asap study). Ann Rheum Dis 2014; 73: 1393-6.

9. Mariette X, Ravaud P, Steinfeld S, Baron G, Goetz J, Hachulla E, et al. Inefficacy of infliximab in primary sjogren's syndrome: Results of the randomized, controlled trial of remicade in primary sjogren's syndrome (tripss). Arthr Rheumat 2004; 50: 1270-6.

10. Norheim KB, Harboe E, Goransson LG, Omdal R. Interleukin-1 inhibition and fatigue in primary sjogren's syndrome--a double blind, randomised clinical trial. PloS one 2012; 7: e30123.

11. Remuzzi G, Lesti M, Gotti E, Ganeva M, Dimitrov BD, Ene-Iordache B, et al. Mycophenolate mofetil versus azathioprine for prevention of acute rejection in renal transplantation (myss): A randomised trial. Lancet (London, England) 2004; 364: 503-12.

12. Tunnicliffe DJ, Palmer SC, Henderson L, Masson P, Craig JC, Tong A, et al. Immunosuppressive treatment for proliferative lupus nephritis. Cochrane Database Syst Rev 2018; 6: Cd002922.

13. Jones RB, Hiemstra TF, Ballarin J, Blockmans DE, Brogan P, Bruchfeld A, et al. Mycophenolate mofetil versus cyclophosphamide for remission induction in anca-associated vasculitis: A randomised, non-inferiority trial. Ann Rheum Dis 2019; 78: 399-405. 
14. Walsh M, James M, Jayne D, Tonelli M, Manns BJ, Hemmelgarn BR. Mycophenolate mofetil for induction therapy of lupus nephritis: A systematic review and meta-analysis. Clin J Am Soc Nephrol 2007; 2: 968-75.

15. Dooley MA, Jayne D, Ginzler EM, Isenberg D, Olsen NJ, Wofsy D, et al. Mycophenolate versus azathioprine as maintenance therapy for lupus nephritis. N Engl J Med 2011; 365: 1886-95.

16. Hahn BH, McMahon MA, Wilkinson A, Wallace WD, Daikh DI, Fitzgerald JD, et al. American college of rheumatology guidelines for screening, treatment, and management of lupus nephritis. Arthritis Care Res 2012; 64: 797-808.

17. Pontarini E, Lucchesi D, Bombardieri M. Current views on the pathogenesis of sjogren's syndrome. Curr Opin Rheumatol 2018; 30: 215-21.

18. Ahmadi-Simab K, Lamprecht P, Nolle B, Ai M, Gross WL. Successful treatment of refractory anterior scleritis in primary sjogren's syndrome with rituximab. Ann Rheum Dis 2005; 64: 1087-8.

19. Danieli MG, Pettinari L, Morariu R, Monteforte F, Logullo F. Intravenous immunoglobulin and mycophenolate mofetil for long-standing sensory neuronopathy in sjogren's syndrome. Case Reports Immunol 2012; 2012: 186320.

20. Louvet C, Maqdasy S, Tekath M, Grobost V, Rieu V, Ruivard M, et al. Infundibuloneurohypophysitis associated with sjogren syndrome successfully treated with mycophenolate mofetil: A case report. Medicine (Baltimore) 2016; 95: e3132.

21. Fialho SC, Bergamaschi S, Neves FS, Zimmermann AF, Castro GR, Pereira IA. Mycophenolate mofetil in primary sjogren's syndrome: A treatment option for agranulocytosis. Rev Bras Reumatol 2012; 52: 297-9.

22. Evans RD, Laing CM, Ciurtin C, Walsh SB. Tubulointerstitial nephritis in primary sjogren syndrome: Clinical manifestations and response to treatment. BMC Musculoskelet Disord 2016; 17: 2.

23. Wang CC, Shiang JC, Huang WT, Lin SH. Hypokalemic paralysis as primary presentation of fanconi syndrome associated with sjogren syndrome. J Clin Rheumatol 2010; 16: 178-80.

24. Pereira PR, Viala K, Maisonobe T, Haroche J, Mathian A, Hie M, et al. Sjogren sensory neuronopathy (sjogren ganglionopathy): Long-term outcome and treatment response in a series of 13 cases. Medicine (Baltimore) 2016; 95: e3632.
25. Willeke P, Schluter B, Becker H, Schotte H, Domschke W, Gaubitz M. Mycophenolate sodium treatment in patients with primary sjogren syndrome: A pilot trial. Arthritis Res Ther 2007; 9: R115.

26. Naniwa T, Takeda Y. Long-term remission of pulmonary veno-occlusive disease associated with primary sjogren's syndrome following immunosuppressive therapy. Mod Rheumatol 2011; 21: 637-40.

27. Hawley RJ, Hendricks WT. Treatment of sjogren syndrome myelopathy with azathioprine and steroids. Arch Neurol 2002; 59: 875; author reply 876.

28. Price EJ, Rigby SP, Clancy U, Venables PJ. A double blind placebo controlled trial of azathioprine in the treatment of primary sjogren's syndrome. J Rheumatol 1998; 25: 896-9.

29. Ogasawara H, Sekiya M, Murashima A, Hishikawa T, Tokano Y, Sekigawa I, et al. Very low-dose cyclosporin treatment of steroid-resistant interstitial pneumonitis associated with sjogren's syndrome. Clin Rheumatol 1998; 17: 160-2.

30. Schnabel A, Reuter M, Gross WL. Intravenous pulse cyclophosphamide in the treatment of interstitial lung disease due to collagen vascular diseases. Arthr Rheumat 1998; 41: 1215-20.

31. Kedor C, Hagemann A, Zernicke J, Mattat K, Callhoff J, Feist E. Effectiveness and safety of low-dose cyclosporine a in patients with primary sjögren's syndrome (pss) with articular involvement - results of a pilot study. Ann Rheum Dis 2015; 74(Suppl 2): Thu0399.341.

32. van Woerkom JM, Kruize AA, Geenen R, van Roon EN, Goldschmeding $\mathrm{R}$, Verstappen SM, et al. Safety and efficacy of leflunomide in primary sjögren's syndrome: A phase ii pilot study. Ann Rheum Dis 2007; 66: 1026-32.

33. Ramos-Casals M, Brito-Zerón P, Bombardieri S, Bootsma H, De Vita S, Dörner T, et al. Eular recommendations for the management of sjögren's syndrome with topical and systemic therapies. Ann Rheum Dis 2020; 79: 3-18.

How to cite this article: Chen W, Jin Lin J. Mycophenolate for the treatment of primary Sjögren's syndrome. J Transl Intern Med 2020; 8: 146-9. 